\title{
1. Introduction: think like a storyteller
}

Academics are a privileged lot. Our job is to (1) think of questions other people haven't thought of and identify questions that haven't been answered, (2) figure out how to answer them, (3) do it, and then (4) tell the story. However, if your doctoral training was anything like mine, or like most of the doctoral programs I've been involved in or exposed to in the twenty-plus years since receiving my degree, the bulk of your training focused on parts two and three (i.e., research design and analytical techniques), with a reasonable amount of attention given to part 1 in your theory and content seminars, and almost no attention given to part 4-storytelling. Indeed, I'm guessing the term "storytelling" rarely, if ever, came up, and formal discussions of writing were likely relegated to one session in a research design seminar, if covered at all. Even in the professional development seminars and workshops offered at major academic association conferences, the bulk of attention is given to research methods and other topics related to figuring out how to answer the interesting questions we come up with, and the doing of it.

However, storytelling is what we do in every article, book chapter and book we write; in every presentation we give; and in every class we teach. Data does not speak for itself; the author must set the context for interpretation, ensure readers understand and accept the question's importance, and finally frame and interpret the implications of the results in ways that give the data meaning.

For example, the science historian Matthew Stanley (2019) provided a fascinating account of how British astronomer Arthur Eddington managed to build interest in and provide definitive proof for Albert Einstein's general theory of relativity during and immediately following World War I. Eddington had to decipher Einstein's complex mathematics and counter-intuitive arguments, which challenged the centuries-long received wisdom of Newtonian physics. Because of the war, only a few individuals outside of Germany were even aware of Einstein's theory, and Eddington had to work through it without the help or input of Einstein himself, who was effectively sealed off in Berlin. Eddington then translated these ideas into more accessible prose-both for other scientists and the public at large-using Gulliver's Travels, Alice in Wonderland and other relatable examples familiar to many people. He and Frank Dyson, the Astronomer Royal and one of the most influential scientists in the UK, then set about drumming up both scientific and popular interest in the theory, and the expedition Eddington was mounting (and Dyson was 
funding) to view a solar eclipse that would allow them to empirically test it. Eddington framed his expedition - which could provide evidence that gravity bends light, a central prediction of relativity theory - as a contest between Newton's and Einstein's theories, making it a battle between two scientific geniuses, thereby creating tension and worldwide interest in the outcome. After finding support for general relativity, he carefully orchestrated the presentation of his findings, marshaling facts and having arguments at the ready to address the objections and challenges Newtonian adherents were sure to raise. After presenting his findings, he continued spreading his interpretation of and support for the theory through both scientific lectures and public speeches before any group that invited him.

While Eddington's efforts spread well beyond the bounds of a single academic study, all the storytelling aspects that any good article or book chapter provides are reflected in his tale. He identified an interesting and important question and attracted attention to it by creating tension or conflict that his study would resolve. He clearly and carefully prepared the terrain so that the audience understood the basic context and arguments, and he laid out the central question tested. After conducting his study and carefully verifying his results, he clearly explained what he did and allowed others to examine his findings so that they were satisfied with their veracity. He then presented his findings and interpreted their meaning, setting them back into the larger framework he had previously established, and explained how they advanced our scientific understanding of gravity, space and time. British astronomer J.J. Thomson noted that "By his eloquence, clearness and literary power [Eddington] persuaded multitudes of people in this country and the Americas that they understand what relativity means" (Stanley, 2019: 317). That is, he did not simply recount the mathematical density of the theory of relativity in dry, esoteric terms; he captured his audience's attention and imagination, and brought the theory to life, through storytelling.

Good writing skills and storytelling tools are critical for successfully exposing your ideas and insights to the world. Scholars have argued (Ashford, 2013; Daft, 1985; Podsakoff, Podsakoff, Mishra \& Escue, 2018) and found (Judge, Cable, Colbert \& Rynes, 2007) that clearly written articles are cited more frequently and are more likely to become high-impact "home runs." As a former Associate Editor for the Academy of Management Journal and reviewer of hundreds of manuscripts for $A M J$ and other journals, I have seen how bad writing inhibits otherwise promising ideas from reaching the public because the papers fail to make it through the review process. Even published articles can have limited influence if their core ideas are inaccessible and they make readers think about taking a nap five minutes after they begin reading. My goal with this book is to help you improve your writing and increase the chances your insights are read and understood. 
One of the most enduring and pernicious falsehoods perpetuated in academia is that being boring equals being rigorous. In this book I explain and show how scholars use the structure and tools of storytelling to make academic writing more accessible, influential and easier to read without "dumbing down" or reducing the rigor of their argumentation and work. Based on my experience and that of other authors, I also provide insights on how to approach the writing and publishing processes. I draw not only from my own experiences and work by others on academic writing, but also from noted authors of fiction and nonfiction who face many of the same struggles, and who provide insights on how to better convey your ideas to others.

In order to creatively express your ideas you have to understand the constraints and demands of the form you are writing in. I have heard complaints about the journal article format and how it inhibits writers' abilities to develop and express their ideas. My response to such whining is, "Does that mean you can't be creative writing a haiku, then, or a sonnet, because they have restrictive forms?"

Every writing form, from limericks to novels to academic journal articles, has specific structures and norms. Forms provide structure that help readers know what to expect and how to find meaning. While some forms are more flexible than others, the creativity comes from successfully conveying what you want within the bounds of the form, not from devising a new and unfamiliar form. Successful academic writers, rather than complaining about the strictures of the journal article form, figure out how to work successfully within it. In this book I discuss the general form of a journal article and what each section needs to contain, as well as the commonalities and differences across theory only, empirical quantitative and empirical qualitative articles. I also show how the structure of a drama can be laid over the general article structure, and how to employ the tools of storytelling within each section to make academic articles engaging and readable.

\section{WRITING VERSUS TYPING}

People are also often stressed by and struggle with the writing process because they conflate writing with typing. Typing occurs when you sit in front of your keyboard, as I am now, and transcribe your thoughts onto the screen (or, for a few of my older colleagues, put pen to paper, letting others do the typing). Although writing occurs during typing, it also occurs when you are far away from your computer. I have spent many dog walks thinking about how to open this chapter, for example, as well as about other aspects of this book. I've also engaged in writing-laying out the structure, logic and examples I will use in this book or in my academic work - while mowing the lawn, cooking and hiking in the woods. Does this make me an obsessive workaholic? Maybe. 
But it also illustrates that writing takes place when you are thinking about your story and what you want to say, not just when you are typing it up. I will discuss the pitfalls and challenges of the writing process, but also the many ways to do it in a healthy and productive way, so that you actually put together something you are proud of and get it out the door.

\section{ADDITIONAL PROCESS ISSUES}

Odds are that most research you produce is co-authored with someone else. Fewer and fewer articles these days are sole-authored, and as productivity demands for annual reviews and promotion and tenure increase it is difficult if not impossible to generate the required amount of research all by yourself. Sole-authoring is less efficient, and a lot less fun. However, identifying and figuring out how to work with co-authors can be challenging, and most scholars with any experience have some co-author horror stories they can share. At the same time, I view writing as an inherently social activity-even though much of it occurs while you are alone - and good collaborators not only make the process more enjoyable, they help produce research that is better than any one of you could have come up with on your own. Thus, this book also covers issues of co-authorship, including selecting, working with and, if necessary, firing co-authors; determining authorship order; and putting co-authored papers together so they speak with one voice.

This takes us to what happens once your article is written. If it is a scholarly journal article, then the next step is to send it out for peer review. There is probably no other aspect of publishing research steeped in more dread, myth and urban legend than the review process. Much of the received wisdom about the review process, editors' motivations, etc., simply isn't true. Yes, it can be dispiriting and ego-damaging even when you are successful, and there are plenty of bad reviewers and editors out there. However, I can say that without exception every paper I've published has improved for having gone through the review process; whether because of ideas and insights offered by the many good editors and reviewers I've encountered, or because overcoming lazy reviewers or poorly done reviews has forced me to think through issues and sharpen my writing so that even a lazy reader can't miss the point. I've also seen many papers fail because the authors didn't manage the review process well; for example, by misinterpreting or making strategic errors in responding to comments, failing to engage with the reviewers' comments entirely, or being overly accommodating and forgetting who the authors of the paper actually are. Thus, I also address the review process and how to manage it successfully.

While publishing research comprises a significant amount of our writing time, we also engage in other types of writing in doing our jobs. Everyone 
drafts cover letters when they go on the job market, and research statements for use in hiring, annual reviews and the promotion and tenure process. You'll likely need money to fund your research, so you will also at some point write research grant proposals. I will spend time talking about these other kinds of writing as well, and what good writing of each type looks like.

\section{THE BOOK'S STRUCTURE}

This book is intended for any academic, at any stage of career, who is interested in improving their writing. It can also serve as a primary text for graduate student writing courses, and selected chapters could be used as readings in introductory research design courses and other courses that are either primarily focused on writing or teach writing as a core component of the course. I am a management scholar, which influences some of the particulars I discuss, especially with respect to article structure and aspects of the review process. Many of my examples will also come from the management literature because it's what I know best. However, much of this book is applicable to scholars publishing in any business discipline, or in related social sciences such as psychology, sociology and economics.

Chapters 2-4 focus on the toolkit you'll need to employ storytelling in your academic writing. Chapter 2 applies the five-act structure of drama to academic storytelling, and discusses other structural aspects such as characters, theme and storylines. Chapter 3 introduces storytelling tools, such as putting a human face on your work, motion and pacing, and showing and telling. Chapter 4 covers the building blocks of storytelling-words, sentences and paragraphs. It focuses on how to produce clear, active prose and on paying attention to the sound and cadence of your writing.

The next section of the book focuses on the article's structure, and what goes into each part. Chapter 5 addresses the Introduction (or opening), Chapter 6 covers Theory Development and Hypotheses, Chapter 7 focuses on presenting the Methods and Results, and Chapter 8 talks about how to write an effective Discussion section. In each of these chapters I cover what a good section contains and why, as well the role the section plays in the overall structure of the story. Chapter 9 brings it all together by considering the similarities and differences in writing theory and empirical qualitative articles, and the differences between writing articles and book chapters.

The book's final section largely addresses process issues. Applying the structure and tools of storytelling and developing each section of the paper can seem easy when considered as abstract concepts, but can be devilishly hard to actually do; and once the paper is ready for review, understanding how to navigate the review process is critical. Thus, Chapter 10 focuses on the writing process, Chapter 11 on the co-authoring process, and Chapter 12 on the review 
process. I also provide some guidance on the other types of writing (grant proposals, research statements and cover letters) that academics do in Chapter 13. Chapter 14 finishes the book with my thoughts on the pleasures of writing, and of writing well.

Although I wrote these chapters with a particular order in mind, I also tried to write them so that they do not have to be read in sequence to be helpful. If there are particular topics you are interested in, you can head right to that chapter without, for the most part, getting lost. This is a nuts-and-bolts book on how to generate good, readable academic articles. I do not engage in debates on the philosophy of science and the nature of knowledge. I hope you find it helpful and thought-provoking. Now, on to storytelling. 